Sādhanā Vol. 37, Part 4, August 2012, pp. 493-502. (C) Indian Academy of Sciences

\title{
Synthesis of carbon fibre-reinforced, silicon carbide composites by soft-solution approach
}

\author{
N PADMAVATHI $^{1}$, P GHOSAL $^{1}, \mathrm{~N}_{\text {ESWARA PRASAD }}^{2, *}$, \\ $\mathrm{J} \mathrm{SUBRAMANYAM}^{1}$ and $\mathrm{K} \mathrm{K} \mathrm{RAY}^{3}$
}
${ }^{1}$ Defence Metallurgical Research Laboratory (DMRL), DRDO, PO Kanchanbagh, Hyderabad 500 058, India
${ }^{2}$ Regional Centre for Military Airworthiness (Materials), CEMILAC, DRDO, PO Kanchanbagh, Hyderabad 500 058, India
${ }^{3}$ Department of Metallurgical and Materials Engineering, Indian Institute
of Technology, Kharagpur 721302, India
e-mail: nep@cemilac.drdo.in

MS received 27 October 2011; revised 5 June 2012; accepted 19 June 2012

\begin{abstract}
The aim of the present work centers on synthesizing and characterizing carbon fibre $\left(\mathrm{C}_{\mathrm{f}}\right)$ reinforced, silicon carbide matrix composites which are considered to have potential applications in aerospace and automobile industry. A series of composites, namely the $\mathrm{C}_{\mathrm{f}}-\mathrm{SiC}, \mathrm{C}_{\mathrm{f}}-(\mathrm{SiC}+\mathrm{ZrC}), \mathrm{C}_{\mathrm{f}}-\left(\mathrm{SiC}+\mathrm{ZrB}_{2}\right)$, and $\mathrm{C}_{\mathrm{f}}-\left(\mathrm{SiC}+\mathrm{ZrO}_{2}\right)$, have been prepared by a proposed soft-solution approach. This approach involves the use of water-soluble precursors of colloidal silica, sucrose, zirconium oxychloride, and boric acid as sources of silica, carbon, zirconia, and boron oxide, respectively to achieve the desired matrices through drying, carbonization and carbothermal reduction. The prepared powders and the composites were characterized by thermal analysis, X-ray diffraction (XRD), optical microscopy, scanning electron microscopy (SEM) and energy dispersive spectroscopy (EDS) analyses to assess the phase formation and microstructure of the materials, apart from assessment of their tensile properties. The study shows that the soft-solution process yields matrices with finer crystallite sizes, having homogeneous distribution of the constituent phases of either the powders or of the composite matrices. The role of the additional phases on the tensile properties of the composites has been discussed using consideration of thermal stresses at fibre-matrix interface; whereas the role of the carbothermal reduction temperature in determining these properties has been explained using the interfacial characteristics of the fibre-matrix. Addition of $\mathrm{ZrO}_{2}$ in the matrix of $\mathrm{SiC}$ has shown to improve the properties of $\mathrm{C}_{\mathrm{f}}-\mathrm{SiC}$ composites considerably. The results of this investigation unambiguously demonstrate that aqueous solution-based processing can be used for fabrication of these composites in relatively shorter time in an environmental friendly manner without using any expensive equipment. The approach is capable
\end{abstract}

*For correspondence 
of yielding composites with different phases in the matrix by simple variation of precursor materials and solutions. The small crystallite sizes, fine particle distribution and low carbothermal reduction temperatures are some of the specific merits of the proposed method.

Keywords. Carbon fibre, silicon carbide composites; soft-solution approach; carbothermal reduction; tensile strength; interfaces.

\section{Introduction}

Significant progress has been made in the field of continuous carbon fibre reinforced silicon carbide matrix $\left(\mathrm{C}_{\mathrm{f}}-\mathrm{SiC}\right)$ composites which are potential candidates for applications where high specific strength with suitable fracture toughness at elevated temperatures are required in several applications, such as automotive brakes, high-efficiency engine systems, chemical reactors and re-entry space vehicles (Rak 2001; Deo et al 2003; Naslain 2005; Zhang et al 2008; Zhang $\&$ Li 2009). But these applications using these composites are limited by the numerous processing difficulties, inadequate material data base, high cost of precursors, expensive equipments for synthesis (Evans \& Zok 1994). Though $\mathrm{C}_{\mathrm{f}}-\mathrm{SiC}$ composites can be synthesized by several methods, each of the existing processing methods is usually associated with limitations specifically pertaining to reproducibility, cost, and environment. Hence, new processing techniques are required to meet the demands to synthesize high performance and cost-effective $\mathrm{C}_{\mathrm{f}}-\mathrm{SiC}$ composite materials in simple, rapid and environmental friendly manner. This investigation is an attempt to meet such challenges for preparing $\mathrm{C}_{\mathrm{f}}-\mathrm{SiC}$ as well as $\mathrm{C}_{\mathrm{f}}-\mathrm{SiC}$ with different additional phases in the matrix of these composites.

A variety of methods, such as chemical vapor infiltration (CVI), polymer impregnation and pyrolysis (PIP), liquid silicon infiltration (LSI), sol-gel, reaction hot-pressing, have been used for the fabrication of $\mathrm{C}_{\mathrm{f}}-\mathrm{SiC}$ composites (Reed 1995). The description of these processes together with their merits and demerits are available in the open literature. In the CVI method, the matrix is prepared by infiltrating the preforms via reaction of gaseous precursors, but this is expensive (Naslain 2004). The PIP method is based on the use of organo metallic pre-ceramic precursors (Mentz et al 2006); higher number of cycles for 'impregnation/pyrolysis' steps are required for manufacturing relatively dense materials by this method which makes it expensive and timeconsuming (Lee et al 2007). In LSI method, porous $\mathrm{C}_{\mathrm{f}}-\mathrm{C}$ is produced by pyrolysis of carbon-rich resin matrix and is then infiltrated with molten silicon (Krenkel 2001); but the presence of free silicon may act as a source of failure. The hot pressing method used for the manufacture of $\mathrm{C}_{\mathrm{f}}-\mathrm{SiC}$ composites is limited by its capacity to form only simple shapes, but often degrades the fibre reinforcement. The sol-gel processing for ceramic composites inherits the merits of fine scale mixing and low densification temperature, which leads to improved properties (Liedtke et al 2007), but is limited due to relatively higher shrinkage during processing. However, there is scanty knowledge about the mechanical property, morphological evolutions, and damage behaviour of $\mathrm{C}_{\mathrm{f}}$-SiC composites under tensile loads. Evaluation of the role of environment on damage mechanisms and the service life of these materials under different types of mechanical loading are needed to assess the applicability of $\mathrm{C}_{\mathrm{f}}-\mathrm{SiC}$ composites (Verrilli et al 2004).

The state-of-the-art of preparation and characterization of $\mathrm{C}_{\mathrm{f}}-\mathrm{SiC}$ composites indicates that (i) the existing methodologies to fabricate these composites have several limitations and (ii) characterization techniques for the microstructural constituents are established, but estimation of the mechanical properties needs careful attention and more emphasis. Based on this background, an 
attempt has been made in this investigation to prepare $\mathrm{C}_{\mathrm{f}}-\mathrm{SiC}$ composites by a new approach with an emphasis on understanding the possible role of additives on the matrix material. The primary goal has been supplemented by characterization of the tensile properties. The main objective of this investigation is to develop a simple and rapid process to fabricate $\mathrm{C}_{\mathrm{f}}-\mathrm{SiC}$ composite which is capable of overcoming a major part of the limitations associated with the existing processes. The steps to fulfill the objectives are: (i) to study the feasibility of soft-solution approach to prepare matrix materials, (ii) to prepare $\mathrm{C}_{\mathrm{f}}-\mathrm{SiC}$ composites without/with additional phases of varying amounts and (iii) microstructural characterization and evaluation of tensile behaviour of the composites. To achieve the objectives, the present work has been divided into following sections: section 2 deals with the preparation of powder/powder mixtures of $\mathrm{SiC}, \mathrm{ZrC}, \mathrm{ZrB}_{2}$ and $\mathrm{ZrO}_{2}$ using soft solution approach. Preparation of $\mathrm{C}_{\mathrm{f}}-\mathrm{SiC}$ composites as well as $\mathrm{C}_{\mathrm{f}}-\mathrm{SiC}$ composites with additional phases like $\mathrm{ZrC}, \mathrm{ZrB}_{2}$ and $\mathrm{ZrO}_{2}$, are given in section 3. Microstructural characterization of the composites is given in section 4 . Tensile behaviour of the $\mathrm{C}_{\mathrm{f}}-\mathrm{SiC}$ composites followed by their statistical analysis are given in section 5. The summary and conclusions are provided in section 6 .

\section{Processing of ceramic powders by soft-solution approach}

Water-soluble colloidal silica (silica, 40 wt.\%), sucrose $\left(\mathrm{C}_{12} \mathrm{H}_{22} \mathrm{O}_{11}\right)$, boric acid $\left(\mathrm{H}_{3} \mathrm{BO}_{3}\right)$ and zirconium oxychloride $\left(\mathrm{ZrOCl}_{2} .8 \mathrm{H}_{2} \mathrm{O}\right)$ have been used as raw materials for achieving silica, carbon, boron oxide $\left(\mathrm{B}_{2} \mathrm{O}_{3}\right)$ and zirconium dioxide $\left(\mathrm{ZrO}_{2}\right)$, respectively. The following stoichiometric reactions are involved with the preparation of the different types of powder mixtures consisting of $\mathrm{SiC}, \mathrm{ZrC}, \mathrm{ZrB}_{2}$ and $\mathrm{ZrO}_{2}$.

$$
\begin{gathered}
\mathrm{SiO}_{2}(\mathrm{~s})+3 \mathrm{C}(\mathrm{s}) \rightarrow \mathrm{SiC}(\mathrm{s})+2 \mathrm{CO}(\mathrm{g}) \uparrow \\
\mathrm{ZrO}_{2}(\mathrm{~s})+3 \mathrm{C}(\mathrm{s}) \rightarrow \mathrm{ZrC}(\mathrm{s})+2 \mathrm{CO}(\mathrm{g}) \uparrow \\
\mathrm{ZrO}_{2}(\mathrm{~s})+\mathrm{B}_{2} \mathrm{O}_{3}(\mathrm{~s})+5 \mathrm{C}(\mathrm{s}) \rightarrow \mathrm{ZrB}_{2}(\mathrm{~s})+5 \mathrm{CO}(\mathrm{g}) \uparrow \\
\mathrm{ZrOCl}_{2} \cdot 8 \mathrm{H}_{2} \mathrm{O}(\mathrm{s}) \rightarrow \mathrm{ZrO}_{2}(\mathrm{~s})+2 \mathrm{HCl}(\mathrm{g}) \uparrow+7 \mathrm{H}_{2} \mathrm{O}(\mathrm{g}) \uparrow
\end{gathered}
$$

The soft-solution approach involves the following steps to prepare the composite powder/powder mixtures: (i) preparation of green precursor solutions by dissolution of the raw materials, (ii) drying of precursor solutions at room temperature at least for 2 days followed by heating at $338 \mathrm{~K}$ for $12 \mathrm{~h}$, (iii) carbonization of dried powders at $773 \mathrm{~K} / 1 \mathrm{~h}$ for the conversion of sucrose to carbon as well as decomposition of zirconium oxychloride to zirconia and boric acid to boria and (iv) finally carbothermal reduction of oxides to carbides/borides at 1873 and $1973 \mathrm{~K}$ for $3 \mathrm{~h}$ as shown by the reactions (1), (2) and (3).

The dried green powders have been first subjected to thermogravimetric analyses to understand the changes in the reactants during heating. The onset temperature of carbothermal reductions for these powders prepared by the soft-solution process is $\leq 1673 \mathrm{~K}$. But the temperatures for carbothermal reductions of silica, zirconia and zirconia+boria are found to be 1788 , 1930 and $1770 \mathrm{~K}$, respectively from thermodynamic data. The lowering of temperature for the onset of carbothermal reduction of green precursors has been attributed to the amorphous nature of the obtained carbon.

XRD patterns of the processed SiC powders in figure 1 primarily indicate the characteristic peaks of cubic $\beta$-SiC. The estimated crystallite sizes of $\beta$-SiC processed at 1873 and $1973 \mathrm{~K}$ are $23.6 \mathrm{~nm}$ and $27.8 \mathrm{~nm}$, respectively. The observed higher crystallite size at $1973 \mathrm{~K}$ can be 


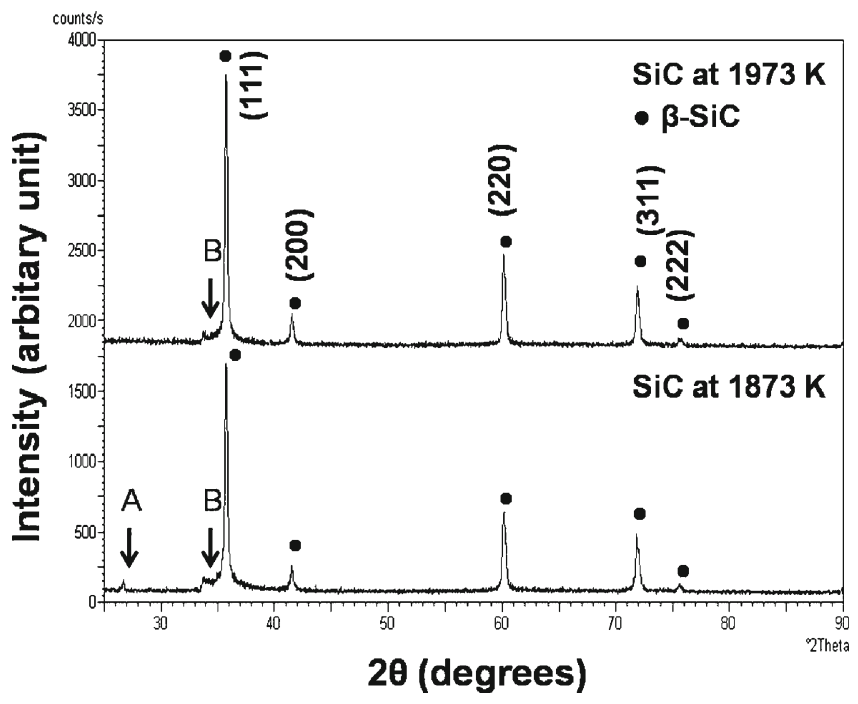

Figure 1. XRD patterns of $\mathrm{SiC}$ powder obtained after carbothermal reduction of silica at 1873 and 1973 K. Peaks at A and B are attributed due to unreacted silica and stacking fault in $\beta$-SiC, respectively.

attributed to the grain growth of $\beta$-SiC. The XRD patterns of the powder/powder mixtures of $\mathrm{ZrC}, \mathrm{ZrB}_{2},(\mathrm{SiC}+\mathrm{ZrC})$ and $\left(\mathrm{SiC}+\mathrm{ZrB}_{2}\right)$ show only the characteristic peaks of $\beta-\mathrm{SiC}, \mathrm{ZrC}$ and $\mathrm{ZrB}_{2}$ free from any un-reacted carbon, silica and zirconia. The XRD of $\mathrm{ZrB}_{2}$ and $\left(\mathrm{SiC}+\mathrm{ZrB}_{2}\right)$ powders prepared using stoichiometric proportions of the reactants as given by Eq. (3) show

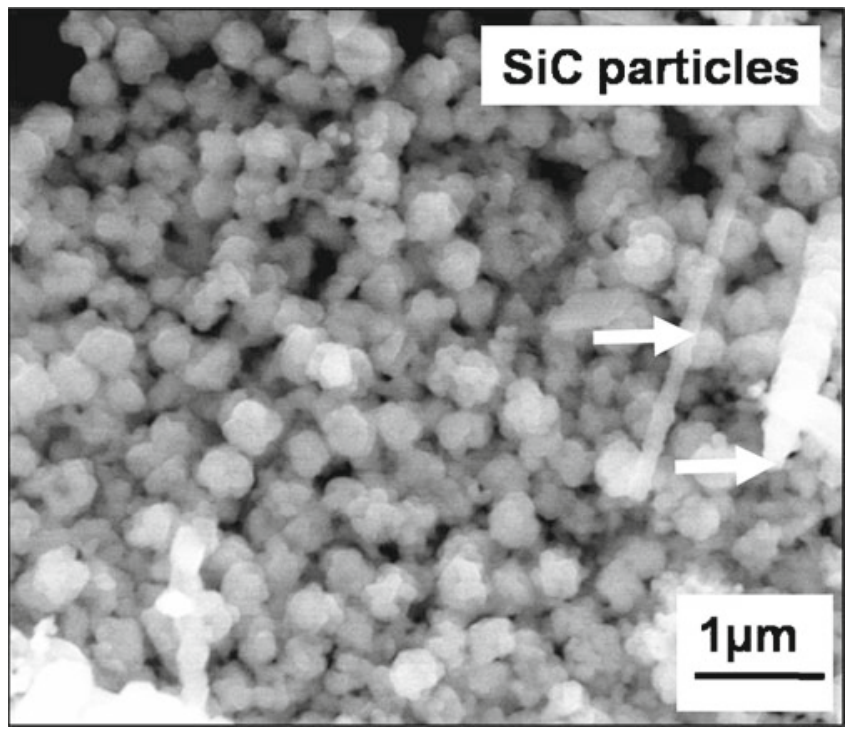

Figure 2. SEM image of SiC powder obtained by carbothermal reduction of silica showing nearly spherical particle morphology. Arrow indicates formation of whiskers. 
additional peaks of $\mathrm{ZrC}$. The estimated crystallite sizes of the obtained phases are in the range of $20-100 \mathrm{~nm}$. The estimated crystallite sizes of $\beta-\mathrm{SiC}$ and $\mathrm{ZrB}_{2}$ in $\left(\mathrm{SiC}+\mathrm{ZrB}{ }_{2}\right)$ powder are found to be 23.3 and $21.7 \mathrm{~nm}$, respectively, suggesting that $\mathrm{SiC}$ can reduce grain growth of $\mathrm{ZrB}_{2}$. Typical SEM image of SiC powder, processed at $1873 \mathrm{~K}$, is shown in figure 2 . The synthesized $\mathrm{SiC}$ powder appears to be agglomerate of a large number of individual crystallites; a few SiC whiskers are also found to form as shown in the same image. The particle size of $\mathrm{SiC}$ is of the order of $200 \mathrm{~nm}$. The carbothermal reduction of silica through soft-solution approach thus generates a composite consisting of $\beta$-SiC particles and $\mathrm{SiC}$ whiskers in the absence of any metal catalysts from outside.

\section{Processing of ceramic composites by soft-solution approach}

The selected carbon fibre is of T-300 grade (PAN type, Volume: 45\%, Tae Kwang Ind. Co. Ltd, Japan) with 12,000 filaments in a tow having filament diameter of about $6 \mu \mathrm{m}$. The details of the precursor solutions for obtaining the desired matrices are similar to that used for preparing the ceramic powder or powder mixtures as described in the preceding section. The preparation of the carbon fibre reinforced composites consisted of the following steps: (i) as-received carbon fibre tow was washed with acetone, (ii) these were vacuum-impregnated with precursor solutions of interest to achieve different matrices like $\mathrm{SiC},(\mathrm{SiC}+\mathrm{ZrC}),\left(\mathrm{SiC}+\mathrm{ZrB}{ }_{2}\right)$ and $\left(\mathrm{SiC}+\mathrm{ZrO}_{2}\right)$, (iii) dried at room temperature for $6 \mathrm{~h}$ and at $338 \mathrm{~K}$ for $2 \mathrm{~h}$ for removal of any excess water. The dried samples were then carbonized at $773 \mathrm{~K}$ for $1 \mathrm{~h}$ in order to convert sucrose to carbon. The sequence involving 'vacuum impregnation, drying and carbonization' was repeated for 6 cycles to improve the density of the composites. Samples were reduced at $1873 \mathrm{~K}$ and $1973 \mathrm{~K}$ for $3 \mathrm{~h}$ in argon atmosphere. The density of the prepared composites has been measured using Archimedes principle. The estimated bulk densities of $\mathrm{C}_{\mathrm{f}}-\mathrm{SiC}$ composites processed at 1873 and $1973 \mathrm{~K}$ are 1870 and $1830 \mathrm{~kg} / \mathrm{m}^{3}$, respectively. The density of the composites increases with increasing amount of the additional phases like $\mathrm{ZrC}, \mathrm{ZrB}_{2}$ and $\mathrm{ZrO}_{2}$.

\section{Microstructure of the composites}

The nature and crystallite sizes of the matrix phases in the microstructures of the prepared composites have been estimated by XRD and SEM. The XRD patterns of processed composites are shown in figure 3 . The $\mathrm{C}_{\mathrm{f}}-\mathrm{SiC}$ composite shows peaks of $\beta$-SiC and graphite originating from carbon fibre, while composites with additional phases also exhibit peaks of the corresponding additional constituents like $\mathrm{ZrC}, \mathrm{ZrB}_{2}$ and $\mathrm{ZrO}_{2}$. The crystallite sizes of the matrix phases have been estimated by Scherrer analyses and these are found to be in the range of 10-40 nm. The crystallite sizes of the matrix phases of the composites are smaller than that of the corresponding phases in the concerned powders, suggesting hindrance to grain growth in the composites by the fibres and additional phases. For example, the presence of $\mathrm{SiC}$ inhibits the grain growth of $\mathrm{ZrB}_{2}$ in $\mathrm{C}_{\mathrm{f}}-\left(\mathrm{SiC}+\mathrm{ZrB}_{2}\right)$ composites and vice versa. Grain growth of the matrix phases is observed with increase in processing temperature; for example the crystallite sizes of $\beta$-SiC, processed at 1873 and $1973 \mathrm{~K}$ are $23.7 \mathrm{~nm}$ and $28.3 \mathrm{~nm}$, respectively.

Typical cross-sectional images of $\mathrm{C}_{\mathrm{f}}$-SiC composites, processed at 1873 and $1973 \mathrm{~K}$ are shown in figure 4. The fibres are embedded in a densified matrix with original shapes and are having nearly homogeneous distribution within the matrix, indicating almost no damage to the fibres during the fabrication of the composites. However, fine cracks (marked with arrows in figure 4b) 


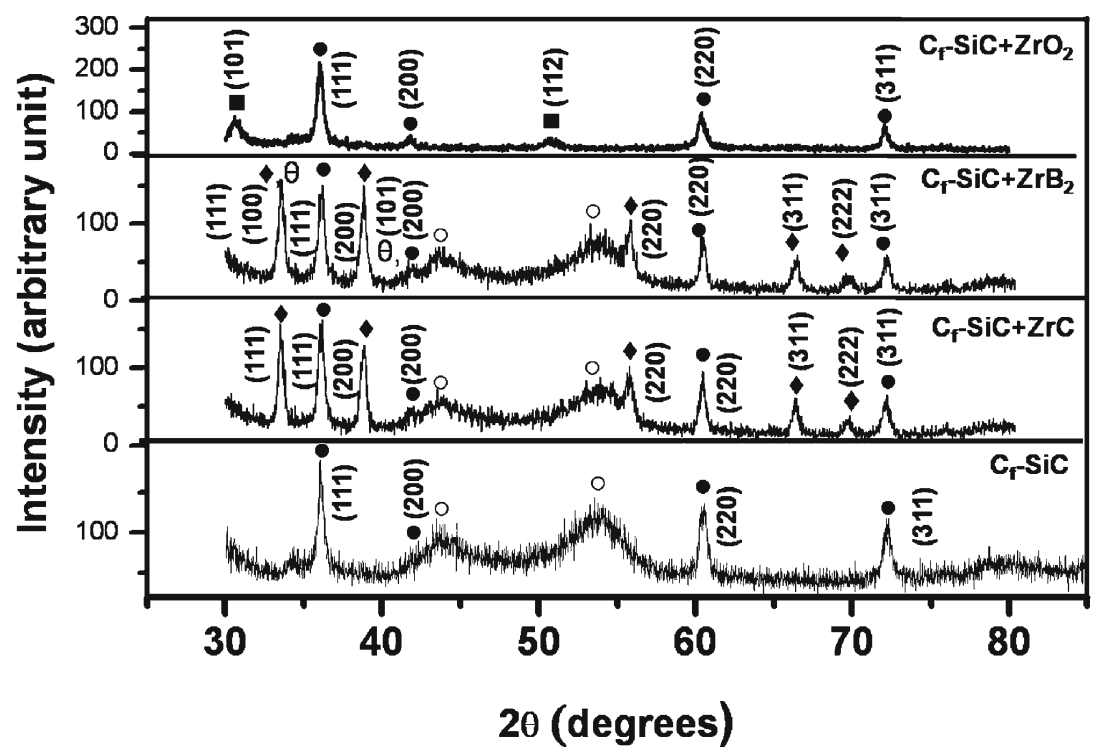

Figure 3. XRD patterns of $\mathrm{C}_{\mathrm{f}}-\mathrm{SiC}$ composites with/without additional phases. The symbols used for the diffraction peaks of the different phases are: $\bullet-\beta-\mathrm{SiC},-\mathrm{ZrC}, \theta-\mathrm{ZrB}_{2}, \square-\mathrm{ZrO}_{2}$ and $\bigcirc$-graphite.

are observed at fibre-matrix interface of the composites, processed at $1973 \mathrm{~K}$; formation of these fine cracks has been attributed to thermal mismatch at fibre-matrix interface at higher processing temperature. Uniform distribution of fibres within the matrix as well as that of the constituent phases is observed in all the composites, processed at 1873 and $1973 \mathrm{~K}$. A thin layer of $\mathrm{ZrC}$ around the carbon fibres in $\mathrm{C}_{\mathrm{f}}-(\mathrm{SiC}+\mathrm{ZrC})$ and $\mathrm{C}_{\mathrm{f}}-\left(\mathrm{SiC}+\mathrm{ZrB}_{2}\right)$ composite, processed at $1973 \mathrm{~K}$ is observed and this is attributed to possible reaction between carbon fibre and $\mathrm{ZrO}_{2}$ at the fibre-matrix interface.

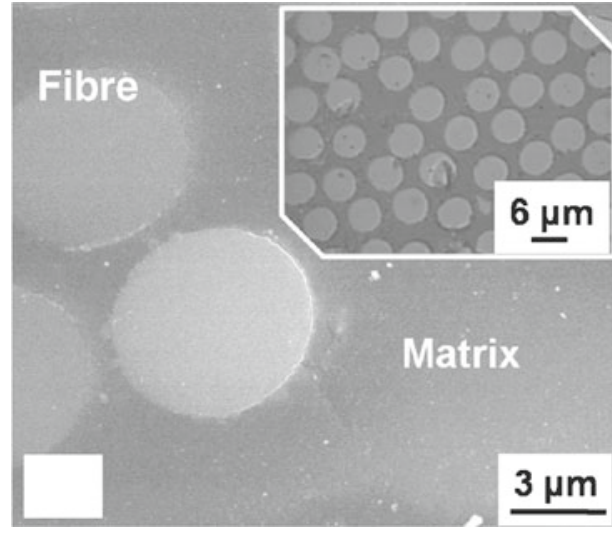

(a)

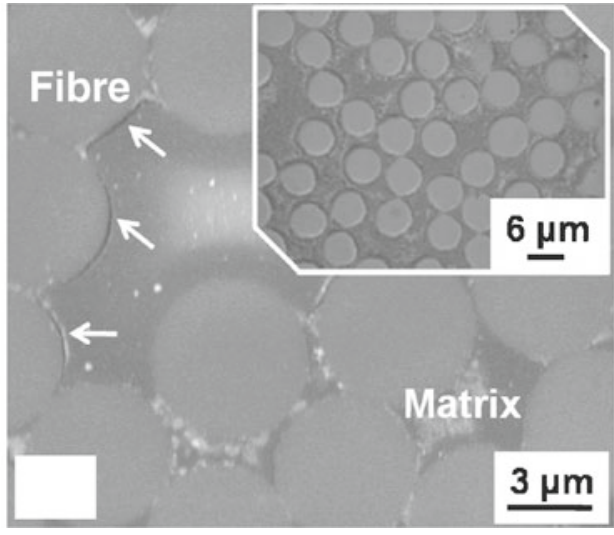

(b)

Figure 4. SEM images of $\mathrm{C}_{\mathrm{f}}$-SiC composites, processed at (a) $1873 \mathrm{~K}$ and (b) at $1973 \mathrm{~K}$. The inserts are optical images at lower magnification. The arrows indicate cracks at fibre-matrix interface. 


\section{Tensile behaviour of composites}

Tensile tests were carried out on specimens having $50 \mathrm{~mm}$ gauge length and $0.657 \mathrm{~mm}$ gauge diameter using paper tabs with suitable adhesive for gripping following ASTM standards (ASTM D4018, 2001). These tests were carried out at a cross head speed of $0.5 \mathrm{~mm} / \mathrm{min}$ using an Instron machine (Model 8801, UK) fitted with $1 \mathrm{kN}$ load cell. For each type of composite, 10 tensile tests were made to estimate average tensile strength and tensile fracture energy, and the results were subjected to Weibull statistical analysis following Lamon (2001).

Typical stress-strain plots of the $\mathrm{C}_{\mathrm{f}}$-tow and $\mathrm{C}_{\mathrm{f}}$-SiC composites are shown in figure 5 . The stress-strain plots of $\mathrm{C}_{\mathrm{f}}$-tow exhibit that stress first increases linearly followed by a non-linear regime up to the maximum stress and then it decreases gradually in a jerky manner till fracture. The jerks after maximum load are attributed to the breakage of individual fibre or bunch of fibres in the fibre tow bundle (figure 5a). The stress-strain behaviour of $\mathrm{C}_{\mathrm{f}}-\mathrm{SiC}$ composites, processed at $1873 \mathrm{~K}$, also exhibits the three different regimes till fracture of $\mathrm{C}_{\mathrm{f}}$-tow. The nonlinear domain of the stress-strain curve for $\mathrm{C}_{\mathrm{f}}-\mathrm{SiC}$ unlike $\mathrm{C}_{\mathrm{f}}$-tow is considered to originate from matrix microcracking while the step-wise failure is indicative of fibre de-bonding and pullout (figure 5b). The stress-strain behaviour of $\mathrm{C}_{\mathrm{f}}-\mathrm{SiC}$ composites, processed at $1973 \mathrm{~K}$, exhibits catastrophic failure which is presumed to be governed by the strengthening of fibre-matrix interfacial bonding (Padmavathi et al 2008).

The variations of tensile strength of $\mathrm{C}_{\mathrm{f}}-\mathrm{SiC}$ with processing temperature as well as that of composites with additional phases are illustrated in figure 6 . The average tensile strength values of $\mathrm{C}_{\mathrm{f}}-\mathrm{SiC}$ composites processed at 1873 and $1973 \mathrm{~K}$ are $316 \pm 48 \mathrm{MPa}$ and $149 \pm 38 \mathrm{MPa}$, respectively. Addition of $\mathrm{ZrC}$ and $\mathrm{ZrB}_{2}$ to the matrix of $\mathrm{C}_{\mathrm{f}}-\mathrm{SiC}$ composites degrades their tensile strength and fracture energy, while addition of $\mathrm{ZrO}_{2}$ improves their tensile properties. The degradation of tensile strength owing to the addition of $\mathrm{ZrC}$ and $\mathrm{ZrB}_{2}$ to the matrix of $\mathrm{C}_{\mathrm{f}}-\mathrm{SiC}$ composites is attributed to the presence of considerable thermal stresses at fibre-matrix interfaces developed due to chemical reaction between the fibres and the matrix. The improvement in tensile strength of $\mathrm{C}_{\mathrm{f}}-\mathrm{SiC}$ composites by the addition of $\mathrm{ZrO}_{2}$, has been explained due to the presence of finer crystallite sizes of $\mathrm{SiC}$ and $\mathrm{t}-\mathrm{ZrO}_{2}$ in the matrix and due to the transformation toughening of $\mathrm{t}-\mathrm{ZrO}_{2}$.

Typical fracture surfaces of the composites, processed at 1873 and $1973 \mathrm{~K}$ are shown in figure 7. The former one (figure 7a) is associated with longer fibre pull-out while the latter one (figure 7b) exhibits shorter fibre pull-out. Since identical fibres and processing conditions except different carbothermal reduction temperatures are used for the preparation of all the composites,

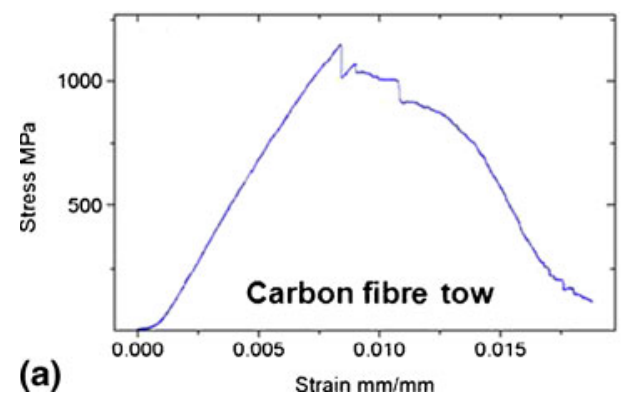

Figure 5. Stress-strain plots of (a) carbon fibre tow and (b) $\mathrm{C}_{\mathrm{f}}-\mathrm{SiC}$ composites. The processing temperatures are shown in parentheses.

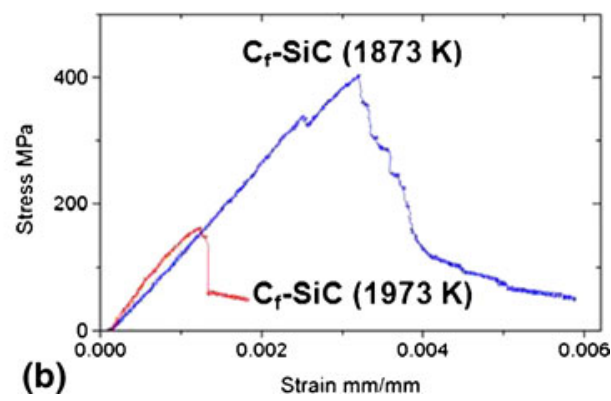




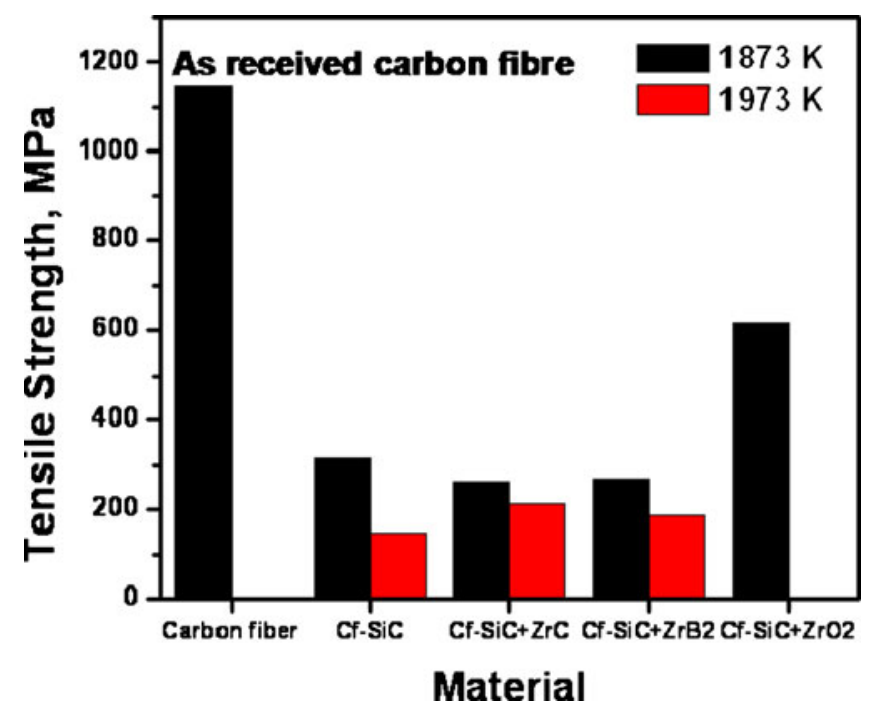

Figure 6. Variation of tensile properties.

it is reasonable to assume that the discrepancy in the mechanism of fracture and hence in tensile properties is due to variation of interfacial characteristics of the fibre and the matrices (Padmavathi et al 2009a \& 2009b). The magnitudes of Weibull shape parameter (m) associated with tensile strength values of $\mathrm{C}_{\mathrm{f}}-\mathrm{SiC}$ composites having additional phases like $\mathrm{ZrC}, \mathrm{ZrB}_{2}$ and $\mathrm{ZrO}_{2}$ indicate, in general, relatively lower scatter whereas the estimated values of Weibull shape parameter associated with fracture energy usually exhibit larger scatter. Limited oxidation tests

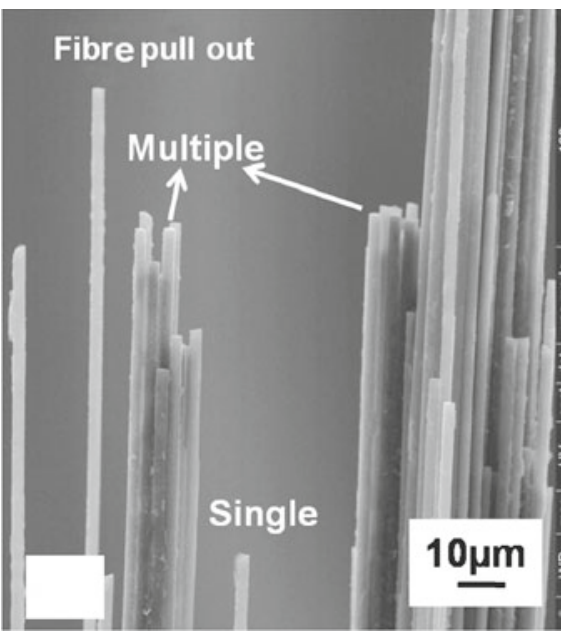

(a)

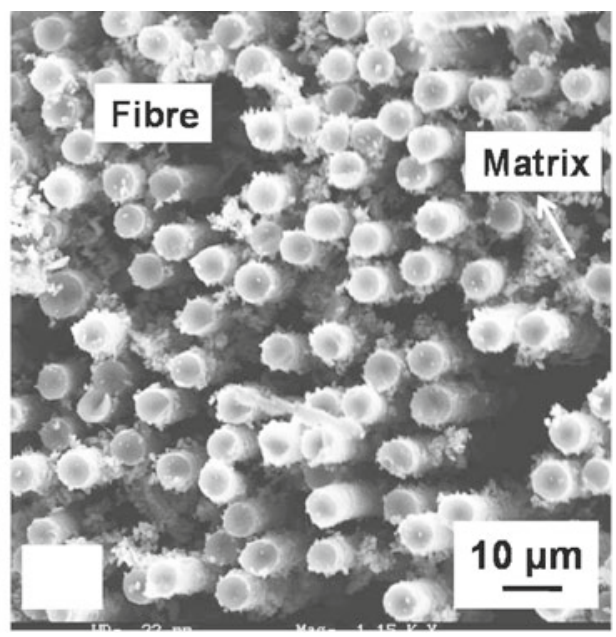

(b)

Figure 7. Fracture surfaces of $\mathrm{C}_{\mathrm{f}}-\mathrm{SiC}$ composites processed at: (a) $1873 \mathrm{~K}$ and (b) $1973 \mathrm{~K}$. 
indicate that the composites with additional phases, i.e., $\mathrm{ZrB}_{2}$ or $\mathrm{ZrC}$ are more resistant to oxidation than their monolithic forms (i.e., $\mathrm{ZrB}_{2}$ or $\mathrm{ZrC}$ ) due to the formation of surface oxide products like $\mathrm{SiO}_{2}$ and $\mathrm{ZrO}_{2}$, which protect the composites against complete degradation by oxidation.

\section{Summary and conclusions}

The feasibility of an aqueous solution-based method to prepare $\mathrm{SiC}, \mathrm{SiC}+\mathrm{ZrC}, \mathrm{SiC}+\mathrm{ZrB} 2$ and $\mathrm{SiC}+\mathrm{ZrO}_{2}$ powders and their composites with carbon fibre reinforcement has been established, this effort is supplemented by suitable characterization of the prepared powders and composites. The methodology has the advantage to prepare the powders and the composites in a relatively shorter time and in an environmentally friendly way. This method bears the potential for extension to the synthesis of metal carbides and borides and their composites. The following conclusions have emerged from this study.

(i) A procedure has been developed to prepare ultra-fine $\mathrm{SiC}$ powders using aqua-based precursor solutions. This approach has been successfully employed to prepare powder/powder mixtures like $\mathrm{SiC},(\mathrm{SiC}+\mathrm{ZrC})$ and $\left(\mathrm{SiC}+\mathrm{ZrB}_{2}\right)$. Small crystallite sizes $(<100 \mathrm{~nm})$ and uniform distribution of the phases have been obtained due to molecular level mixing of the precursor materials.

(ii) The suggested methodology is capable of preparing $\mathrm{C}_{\mathrm{f}}-\mathrm{SiC}, \mathrm{C}_{\mathrm{f}}-(\mathrm{SiC}+\mathrm{ZrC}), \mathrm{C}_{\mathrm{f}}-$ $\left(\mathrm{SiC}+\mathrm{ZrB}_{2}\right)$ and $\mathrm{C}_{\mathrm{f}}-\left(\mathrm{SiC}+\mathrm{ZrO}_{2}\right)$ composites by simple variation of precursor materials and solutions, and are free from un-reacted species.

(iii) The crystallite sizes of all the phases in the synthesized matrices are in the range of 20$40 \mathrm{~nm}$ and the fibres are uniformly distributed within the matrix of the composites at both the processing temperatures of 1873 and $1973 \mathrm{~K}$. A few cracks are observed at the fibrematrix interface of the composites processed at $1973 \mathrm{~K}$.

(iv) Tensile properties of the processed composites are found to be inferior compared to that of carbon fibre tow. The tensile strength and fracture energy of $\mathrm{C}_{\mathrm{f}}-\left(\mathrm{SiC}+\mathrm{ZrO}_{2}\right)$ composites are superior compared to that of $\mathrm{C}_{\mathrm{f}}-\mathrm{SiC}$ composites. The composites processed at $1873 \mathrm{~K}$ exhibited superior properties than those of composites processed at $1973 \mathrm{~K}$. The average values of both tensile strength and fracture energy of $\mathrm{C}_{\mathrm{f}}-\mathrm{SiC}$ composites increase with increasing amounts of additional phases like $\mathrm{ZrC}, \mathrm{ZrB}_{2}$ or $\mathrm{ZrO}_{2}$.

(v) The observed phenomena of long and short fibre pull-out of the composites processed at 1873 and $1973 \mathrm{~K}$, respectively, during their fracture indicate weaker and stronger fibrematrix interfacial bonding, respectively. The nature of the interfacial bonding is governed by generated thermal stresses at the interface, chemical reaction between fibre and matrix and degradation of fibres.

(vi) The magnitudes of Weibull shape parameter $(\mathrm{m})$ associated with the tensile strength values of $\mathrm{C}_{\mathrm{f}}-\mathrm{SiC}$ composites having additional phases like $\mathrm{ZrC}, \mathrm{ZrB}_{2}$ and $\mathrm{ZrO}_{2}$ indicate, in general, that these are associated with lower scatter whereas the estimated values of Weibull shape parameter associated with fracture energy usually exhibit larger scatter.

\section{Acknowledgements}

The authors are grateful to Dr. G Malakondaiah, Distinguished Scientist and Director, Defence Metallurgical Research Institute (DMRL), Hyderabad, India for his kind permission to use the DMRL facilities and also, for his constant encouragement and support. Authors also thank colleagues in the Ceramics \& Composites and Materials Sciences divisions of DMRL for their help 
in conducting this study. One of the authors (NEP) would like to thank Dr. K Tamilmani, Distinguished Scientist and Chief Executive (Airworthiness), CEMILAC, DRDO, Bangalore for his support. Funding from Defense Research Development Organization (DRDO) to carry out these studies is gratefully acknowledged.

\section{References}

ASTM 2001 Standard Test Method for tensile properties of continuous filament carbon and graphite yarns, USA: Strands, Rovings and Tows 15.03: D4018-4081

Deo R B, Starnes J H and Holzwarth R C 2003 'Low-cost composite materials and structures for aircraft applications', Scientific and Technical Aerospace Reports (STAR), USA: NASA, 41(22): 1-1-1-11

Evans A G and Zok F W 1994 Review: The physics and mechanics of fibre-reinforced brittle matrix composites, J. Mater. Sci. 29(15): 3857-3896

Lamon J 2001 A micromechanics-based approach to the mechanical behaviour of brittle-matrix composites, Compos. Sci. Technol. 61: 2259-2272

Lee Sea-Hoon, Weinmann M and Aldinger F 2007 Fabrication of fibre-reinforced ceramic composites by the modified slurry infiltration technique, J. Am. Ceram. Soc. 90(8): 2657-2660

Liedtke V, Olivares I, Langer M and Haruvy Y F 2007 Sol-gel-based carbon/silicon carbide, J. Euro. Ceram. Soc. 27: 1267-1272

Krenkel W 2001 Cost effective processing of CMC composites by melt infiltration (LSI-process), Ceram. Eng. Sci. Proc. 22(3): 443-454

Mentz J, Muller M, Buchkremer P H and Stover D 2006 Carbon-fibre reinforced carbon composites filled with $\mathrm{SiC}$ particles forming a porous matrix, Mater. Sci. Eng. A 425(1-2): 64-69

Naslain R 2004 Design, preparation and properties of non-oxide CMCs for application in engines and nuclear reactors: An overview, Compos. Sci. Technol. 64: 155-170

Naslain R 2005 SiC-Matrix Composites: Non-brittle ceramics for thermo-structural application, Int. J. Appl. Ceram. Technol. 2(2): 75-84

Padmavathi N, Subrahmanyam J, Ghosal P, Ray K K and Sweety K 2008 Preparation of carbon fibre reinforced SiC composites by solution approach, J. Mater. Proc. Technol. 204(1-3): 434-439

Padmavathi N, Subrahmanyam J, Ray K K and Sweety K 2009a Processing of carbon fibre reinforced $(\mathrm{SiC}+\mathrm{ZrC})$ composites by soft-solution approach and their characterization, Ceram. Int. 35: 3447-3454

Padmavathi N, Subrahmanyam J, Ghosal P, Ray K K and Sweety K 2009b New route to process carbon fibre reinforced $\left(\mathrm{SiC}+\mathrm{ZrB}_{2}\right)$ matrix composites, J. Mater. Sci. 44: 3255-3264

Rak Z $2001 \mathrm{C}_{\mathrm{f}} / \mathrm{SiC} / \mathrm{C}$ Composites for tribological application, in high temperature ceramic matrix composite: Collected papers, W. Krenkel, R. Naslain and H. Schneider (eds.), Germany: Weinheim, WILEY-VCH, pp. 820-825

Reed J S 1995 Principles of ceramics processing, New York: John Wiley \& Sons, Second Edition, pp. 295-297

Verrilli M J, Opila E J, Calomino A and Kiser J D 2004 Effect of environment on the stress-rupture behavior of a carbon-fibre-reinforced silicon carbide ceramic matrix composite, J. Am. Ceram. Soc. 87(8): 15361542

Zhang Q and Li G 2009 A review of the application of C/SiC composites in thermal protection system, Multidiscipline Modelling Mater. Struct. 5(2): 199-203

Zhang Y, Zhang L, Cheng L and Xu Y 2008 Tensile behaviour and micro-structural evolution of a carbon/silicon carbide composite in simulated re-entry environments, Mater. Sci. Eng. A 473: 111-118 